\title{
FUNCTIONAL PROPERTIES OF LEAF-LIKE MUSCLE RECEPTORS IN THE FROG SARTORIUS MUSCLE
}

\author{
Fumio Iто \\ Department of Physiology, School of Dentistry, \\ Aichi-Gakuin University, Nagoya
}

ITO, TOYAMA and ITO $^{4)}$ have described stretch receptors with some functional characteristics different from those of spindle receptors in the frog sartorius muscle. The parent nerve fibers from leaf-like expansions on the surface of several extrafusal muscle fibers without capsules, after ramifying in the vicinity of their terminals. Hence the receptor were named "extrafusal receptors" by them. The term "extrafusal receptor", however, is confused with the other muscle receptors found among the extrafusal muscle fibers, for example, free nerve endings described by KOBAYASHI, OsHIMA and TASAKI ${ }^{6}$. In the present study, the term "leaf-like muscle receptor" will be used according to KULCHITSKY ${ }^{7)}$ instead of "extrafusal receptor", and an attempt will be made to differentiate functionally between this receptor and the tendon receptor described in the preceding paper ${ }^{5}$.

\section{METHODS}

The experiments were performed on the frog sartorius nerve-muscle preparation with intact innervation of the 9th dorsal and ventral roots, during the months June November, at a room temperature of about $25^{\circ} \mathrm{C}$. The tendons at each end of the muscle were preserved and tied to a glass hook of a mechano-electric transducer (RCA 5734) and to an electro-magnetic stretcher or to various weights by a thread passing through a pulley. The experimental procedures for stretching or loading the muscle have been fully described in the preceding paper ${ }^{5}$. The discharges of single afferent fibers from the leaf-like receptors were recorded from subdivided 9 th dorsal root filaments. The endings studied were identified as leaf-like receptors by their morphological aspects observed under Köhler illumination without staining and by the conduction velocity of their afferent impulses which ranged from 10 to $20 \mathrm{~m} / \mathrm{sec}^{4)}$.

Twitch or tetanic contractions of the muscle were produced by stimulation of the 9 th ventral root with a single electric pulse of $0.1 \mathrm{msec}$ duration or with repetitive pulses at $100 / \mathrm{sec}$.

Received for publication January 6, 1968

伊藤交雄 


\section{RESULTS}

Impulse discharges during isometric contraction. Twenty seven (about 70\%) out of 39 leaf-like receptors studied responded in the falling phase of the tension curve of a twitch contraction, as illustrated in FIG. 1. The twitch tension thresholds for firing of the receptors ranged between 0.1 and $2 \mathrm{~g}$. FIG. 1A show the dependence of the discharge number and frequency of a leaf-like receptor upon different twitch tensions induced by different stimulus strengths delivered to the 9 th ventral root, leaving the muscle length at $+0 \mathrm{~mm}$. In this case, one discharge occurred when the tension attained $1.7 \mathrm{~g}$ (FIG. 1Aa). The discharge increased in the falling phase of the tension curve with enhancement of the twitch tension according to increase of the stimulus strengths (FIG. $1 \mathrm{Ab}$ and $\mathrm{c}$ ).

In FIG. 1B, the twitch contractions of the muscle were made under isometric conditions from $+0 \mathrm{~mm}$ to $+4 \mathrm{~mm}$ initial lengths, leaving at a suprathreshold level the stimulus strength to the ventral root. The discharge frequency

A

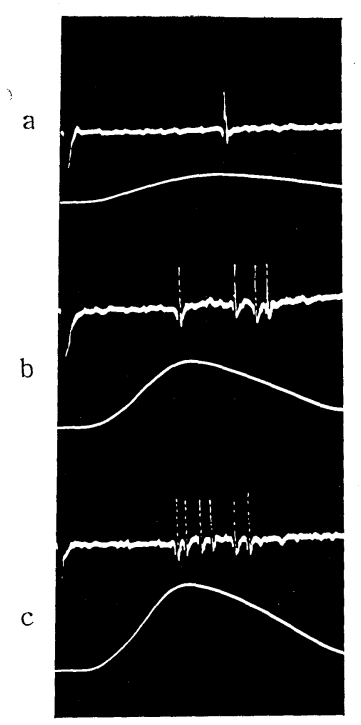

B

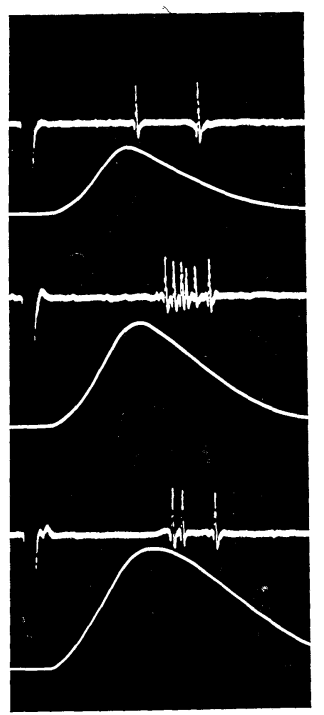

C

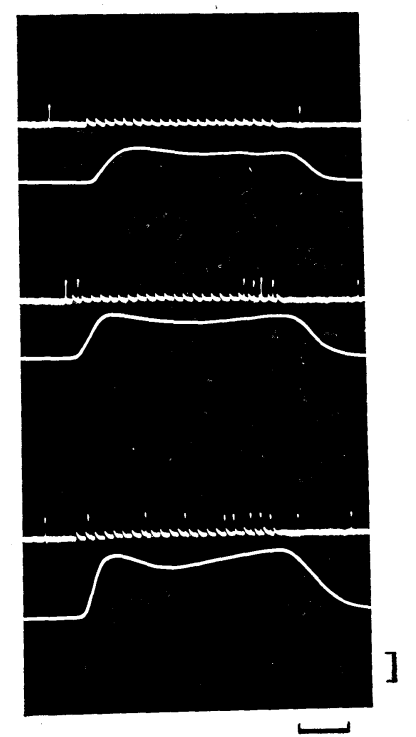

FIG. 1. Simultaneous recording of single unit discharges from leaf-like muscle receptors (upper traces) and of tension changes of the muscle (lower traces) during isometric contractions. A : Responses during different heights of twitch contractions with increase of stimulus strengths (a to c) at $+0 \mathrm{~mm}$ length. B: Responses of the same receptor as A during different heights of twitch concentrations with elongation of the muscle length from $+0 \mathrm{~mm}$ (a) to $+2 \mathrm{~mm}$ (b) and to $+4 \mathrm{~mm}$ (c) under the isometric condition. Calibration : $2 \mathrm{~g}, 10 \mathrm{msec}$. C : Responses during isometric tetanic contractions with increase of stimulus strengths (a to c). A leaf-like receptor discharging at the falling foot of the isometric twitch tension. Calibration: $10 \mathrm{~g}, 0.1 \mathrm{sec}$. 
increased with prolongation of the initial length from $+0 \mathrm{~mm}$ to $+2 \mathrm{~mm}$ (FIG. $1 \mathrm{Ba}$ and $\mathrm{b}$ ), but decreased for over $+4 \mathrm{~mm}$, although the twitch tension increased (FIG. 1Bc).

FIG. 1C shows the responses of a leaf-like receptor during tetanic muscle contractions. The receptor responded in the falling foot of twitch contraction, and was also activated in the falling phase of the tetanic contraction (FIG. $1 \mathrm{C}$ a). When the tension of the tetanic contraction increased to about $15 \mathrm{~g}$ at its highest amount with increase of the stimulus strength, one and four discharges appeared at the onset and during the plateau of the contraction (FIG. 1. Cb). During the tetanic contraction of $20 \mathrm{~g}$ tension, sustained discharges occurred as illustrated in FIG. $1 \mathrm{Cc}$.

Responses of the remaining 12 receptors (about 30\%) appeared in the rising phase of the tension curve of the isometric contractions. The discharge increased with enhancement of the muscle tension from the threshold for the response of the receptors to a level of the tension, but decreased when the tension developed over the level.

Impulse discharges during muscle shortening against loads. When the muscle was loaded with $0.5 \mathrm{~g}$, the muscle was extended to approximately the $+0 \mathrm{~mm}$ length. Three out of 39 receptors responded with a discharge frequency from 0.5 to $1.2 \mathrm{impulses} / \mathrm{sec}$. The other 21 receptors responded with a transient burst of from 1 to 5 impulses during an initial acceleration of the tension developed by the onset of $2 \mathrm{~g}$ of loading (FIG. 2Ca). The load made the extension approximately $10 \%$ greater than at the $+0 \mathrm{~mm}$ length of the muscle. The remaining 15 receptors responded with a transient burst or with phasic discharges of up to 25 impulses/sec frequency during the over-shoot of the tension development with $3 \mathrm{~g}$ or more of loading. These three grades on the thresholds of the leaf-like receptors to the loads were independent of the classification with thresholds of the responses of their receptors during isometric contractions.

When the muscle shortened against $2 \mathrm{~g}$ weight by a single stimulation of the 9th ventral root, the tension recorded at the fixed pelvic end of the muscle deflected triphasically in the main, as had been observed in the preceding paper $^{\text {s). }}$. The receptors discharging at the onset of $2 \mathrm{~g}$ of loading responded with a single spike at the falling phase of the first upward deflection, when its tension developed over $2 \mathrm{~g}$, as illustrated in FIG. 2Aa. With increase of the tension produced by larger stimulus strengths, two spikes occurred at the falling phase of the first upward deflection and at the rising phase of the second respectively, as illustrated in FIG. 2Ab. The further increases in tension produced by increases in stimulus strength resulted in up to 6 spikes at higher frequencies (FIG. 2Ac).

The same receptor as mentioned above also responded with a single discharge at the falling phase of the first upward deflection when the load of $0.5 \mathrm{~g}$ 
was accelerated to $2 \mathrm{~g}$ tensions by the shortening of the muscle (FIG. 2Ba). When the muscle shortened against a $1 \mathrm{~g}$ weight by the same stimulus strength as in Fig. 2Ba, the tension developed $3 \mathrm{~g}$ at the peak of the first upward deflection. Two spikes occurred in the falling phase of the first upward deflection and 3 occurred in the rising phase of the second, as illustrated in FIG. 2Bb. The number and frequency of the spike discharges further increased with increases of tension when the weight was increased, especially showing apparent increases in the second upward deflection, as illustrated in FIG. 2Bc. Similar discharges from the same receptor as mentioned above were also observed in the tension deflections during tetanic shortening of the muscle by repetitive stimulation at $100 / \mathrm{sec}$. One discharge occurred in the falling phase of the upward deflection up to $2 \mathrm{~g}$ tension at the onset of the tetanic shortening (FIG. 2Cb). During an equilibrium state of the tension developments between the tetanic shortening and the muscle loading, no discharge was observed. After cessation of the tetanic shortening, eight discharges occurred at high frequencies during the rising phase of the upward deflection, and one discharge during the rising phase of the damped oscillation, as illustrated in FIG. 2Cc.

A

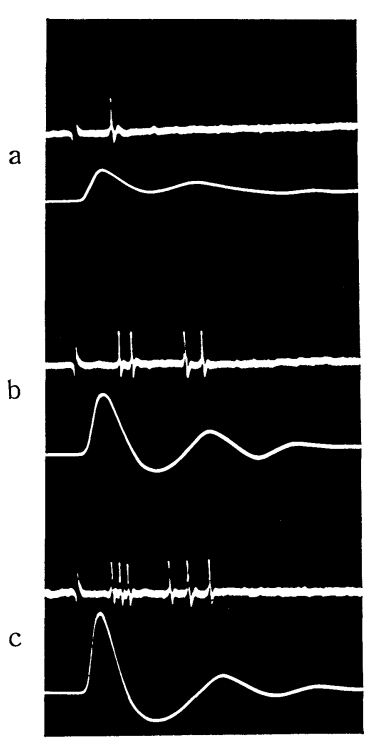

B

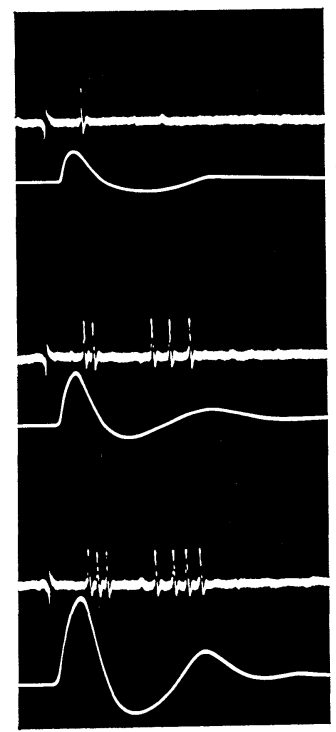

C

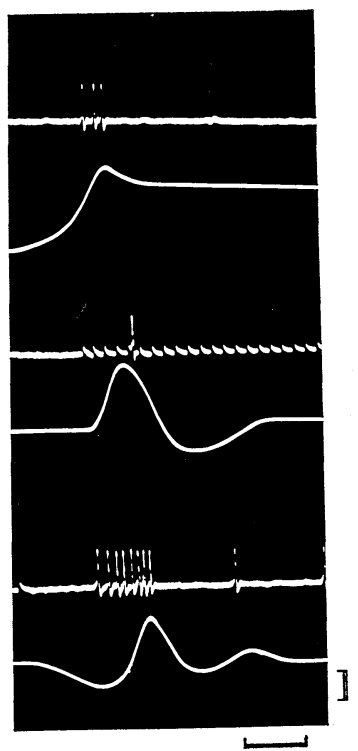

FIG. 2. Simultaneous recording of single unit discharges from a leaf-like muscle receptor (upper traces) and of muscle tension (lower traces) during shortening of the muscle against loads. A: Responses during different amounts of twitch shortenings with increase of stimulus strengths (a to c) against $2 \mathrm{~g}$ load. B: Responses during different amounts of twitch shortenings against different loads of $0.5 \mathrm{~g}$ (a), $1 \mathrm{~g}$ (b) and $2 \mathrm{~g}$ (c). C : Responses at onset of the $2 \mathrm{~g}$ load (a) and at on (b) and off (c) of tetanic shortenings at $100 / \mathrm{sec}$ against $2 \mathrm{~g}$ load. Calibration : $2 \mathrm{~g}, 50 \mathrm{msec}$. 
Impulse discharges during stretch at constant velocities. The leaf-like muscle receptors have been classified into groups ${ }^{4}$ with different thresholds to stretch of the muscle. Twenty four out of 39 receptors responed by extension to less than $120 \%$ of the $+0 \mathrm{~mm}$ initial length, belonging to the lower threshold group. These receptors corresponded to the receptors responding to loading less than $2 \mathrm{~g}$ weights as was described in the preceding chapter. The other 15 receptors transiently discharged by extension to $130 \%$ or more of the $+0 \mathrm{~mm}$ initial length, belonging to the higher threshold group. These receptors were those responding to loading of more than $3 \mathrm{~g}$. These two groups of the receptors were independent of the groups classified by the responses during isometric contractions. The receptors belonging to the lower threshold group did not respond to stretching by $2 \mathrm{~mm}$ from $+0 \mathrm{~mm}$ initial length of the muscle, except for three receptors discharging spontaneously at $+0 \mathrm{~mm}$ initial length. When the muscle was stretched by $2 \mathrm{~mm}$ from $+2 \mathrm{~mm}$ initial length, one or a few discharges occurred at the completion of the dynamic phase of the stretch. With stretching by $2 \mathrm{~mm}$ from $+4 \mathrm{~mm}$ initial length, the discharges initiated always at $0.8 \mathrm{~mm}$ extension from the initial length at different velocities and maintained during extension of the muscle, as illustrated in FIG. 3. An initial transient rise of the discharge frequency was often observed at about $1.2 \mathrm{~mm}$

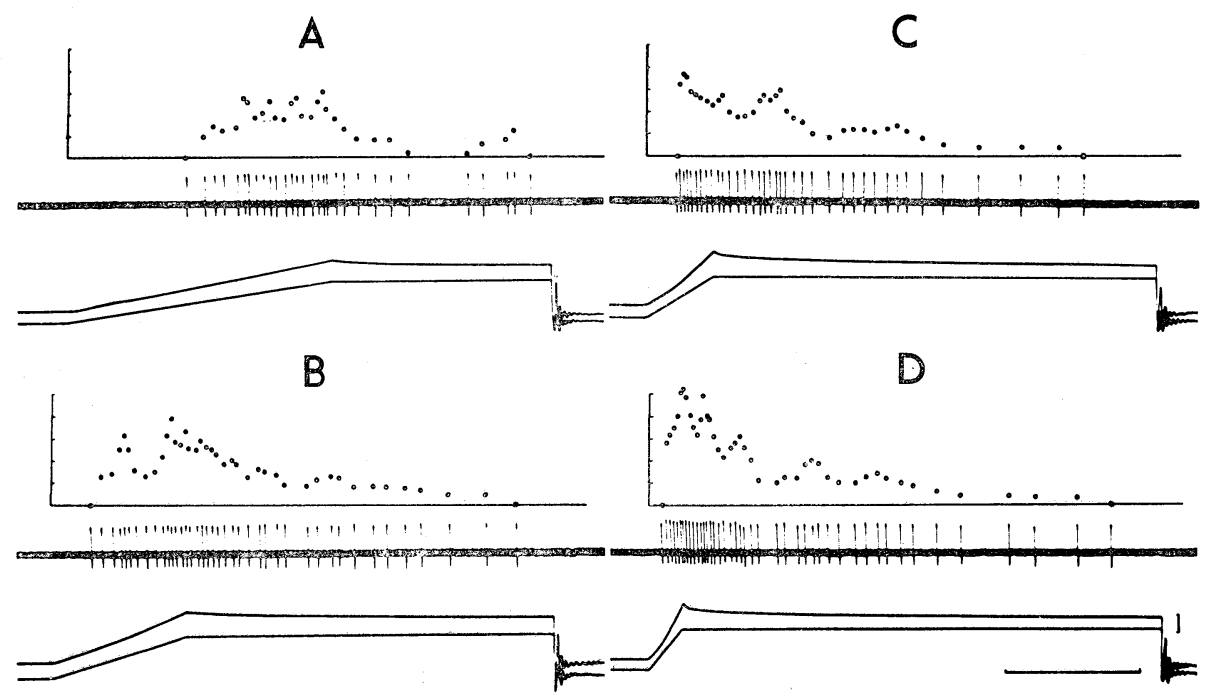

FIG. 3. Responses of a lower threshold leaf-like muscle receptor (upper traces of each record) during muscle stretch by $2 \mathrm{~mm}$ from $+4 \mathrm{~mm}$ initial length at velocities of 1.0 (A), 2.0 (B), 4.0 (C) and $8.0 \mathrm{~mm} / \mathrm{sec}$ (D), recorded simultaneously with the displacement (lower traces) and the tension changes (middle traces) of the muscle. Calibration: $1 \mathrm{~g}$ for tension, $1 \mathrm{sec}$. The frequency is represented by the reciprocal of the mean of the successive two intervals of spike initiation and manually plotted at the time of the middle spike on the head of each record. Scale: 10 impulses/sec. 
extension from the initial length, and its maximal value increased with enhancement of the velocity of muscle stretching, as illustrated in FIG. 3A, B and C. The initial transient rise appeared with a considerable delay after an initial acceleration of the tension as illustrated in each record of FIG. 3. After the frequency decreased from the initial transient rise, the frequency again increased and attained a peak at the completion of the dynamic phase of stretch. The peak frequency was sometimes exceeded by the maximal value of the initial transient rise of discharge frequency, as illustrated in FIG. 3C. The discharge frequency decreased after the completion of the stretch, often with a damped oscillation which is apparent at the higher velocities of the stretch as shown in FIG. 3C and D. The static indexes were independent of the stretch velocity, but they were not always a constant value at different velocities of stretching, because the frequency fluctuated. The index was determined by the mean frequency between 0.4 and $0.6 \mathrm{sec}$ after completion of the stretch, it was approximately $22 \mathrm{impulses/sec} \mathrm{through} \mathrm{different} \mathrm{velocities} \mathrm{in} \mathrm{the} \mathrm{case} \mathrm{of}$ FIG. 3. The dynamic index was apparently dependent upon the velocity of stretching.

When the muscle was stretched by $2 \mathrm{~mm}$ from $+6 \mathrm{~mm}$ initial length, the discharge frequencies of the same receptors as mentioned above were generally at higher levels in comparison with those for $+4 \mathrm{~mm}$ initial length, as illustrated

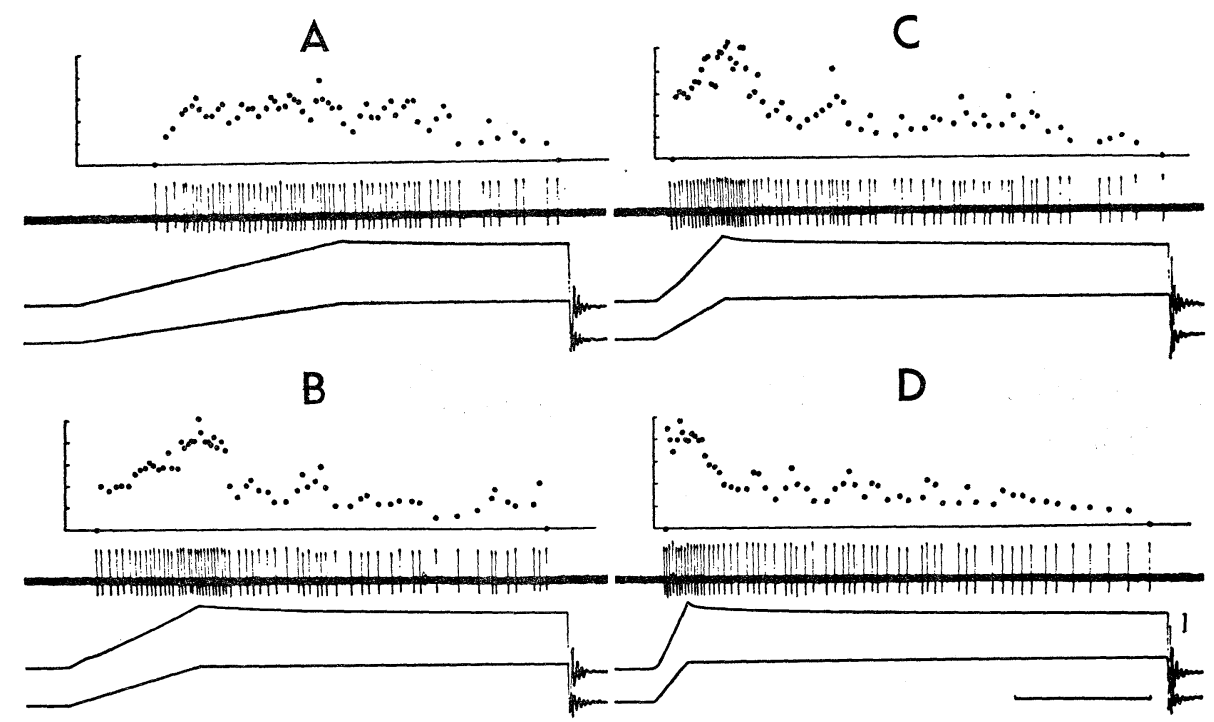

FIG. 4. Responses of the same receptor as shown in FIG. 3 (upper traces of each record) during muscle stretch by $2 \mathrm{~mm}$ from $+6 \mathrm{~mm}$ initial length at the velocities of 1.0 (A), 2.0 (B), 4.0 (C) and 8.0 (D), recorded simultaneously with the displacement (lower traces) and the tension changes (middle traces) of the muscle. Calibration: $1 \mathrm{~g}$ for tension, $1 \mathrm{sec}$. The frequency is plotted on the head of each record. Scale: 10 impulses/sec. 


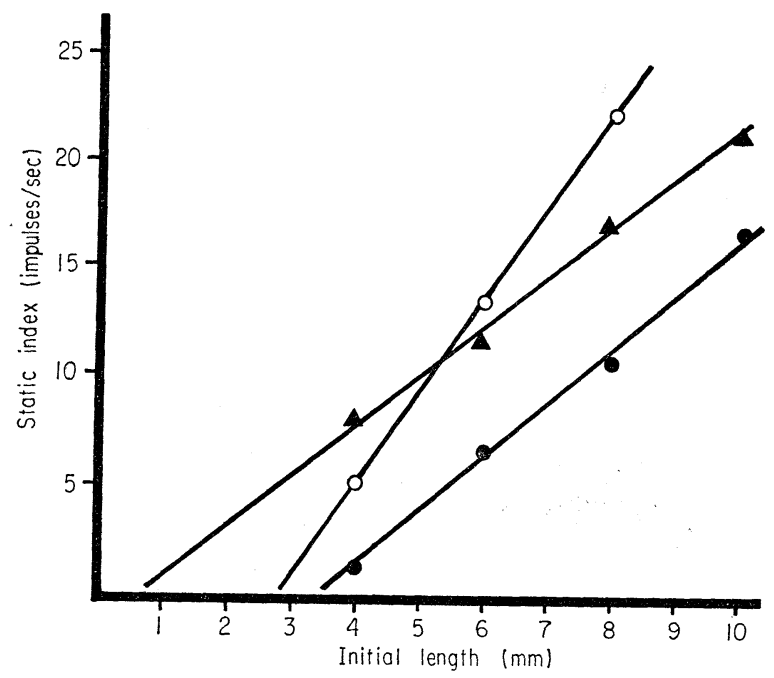

FIG. 5. Showing linear increase of static index (ordinate) with elongation of the initial length (abscissa), on the representative three receptors belonging to the lower threshold leaf-like receptor.

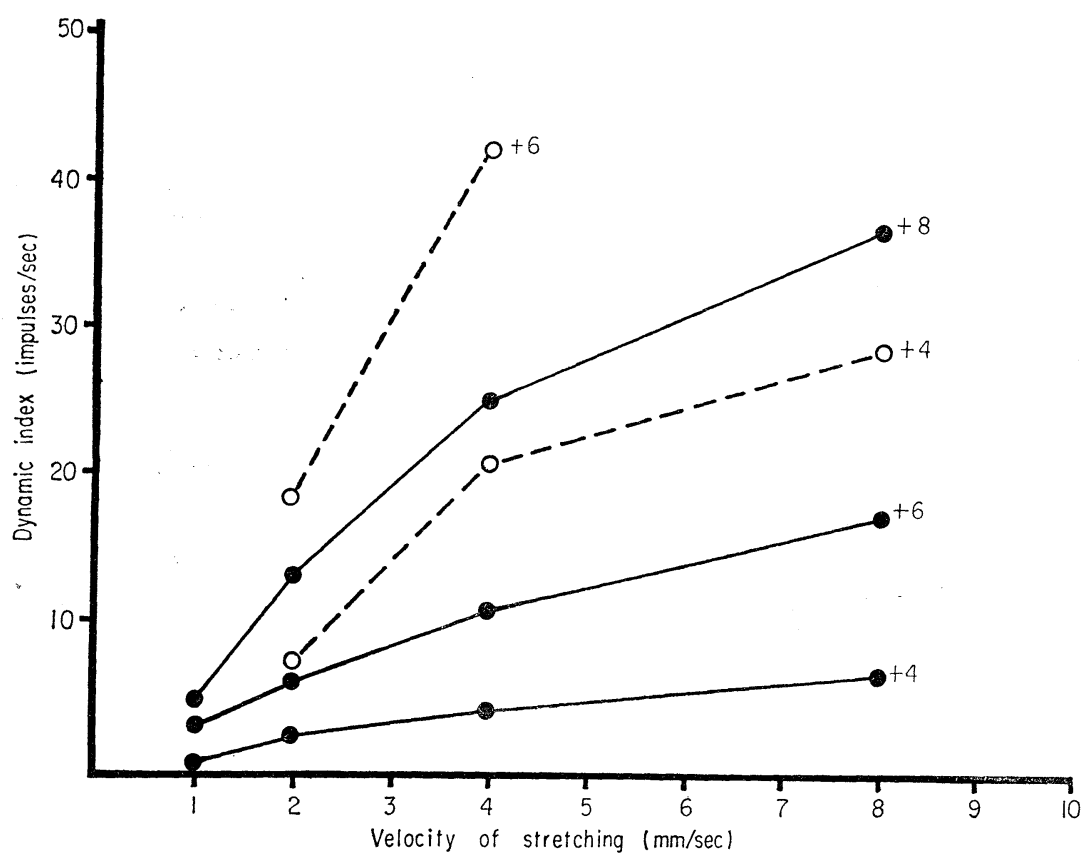

FIG. 6. Showing dependence of the magnitude of the dynamic index (ordinate) upon the stretch velocity (abscissa), and also upon the initial length of the muscle. The indexes of a lower threshold leaf-like receptor (solid lines) appeared to be lower than those of a higher threshold receptor (dotted lines). 
in FIG. 4. The initial transient rise of the frequency was also observed in FIG. 4 as well as in FIG. 3. The mean static index was at 26 impulses/sec at $+6 \mathrm{~mm}$, being independent of the velocity of the stretch. FIG. 5 shows a linear relationship between the static index and the initial length on 3 examples of the lower threshold leaf-like receptors. The angle of the linear slope represents the static sensitivity of the receptor. The amount of the sensitivity measured for leaf-like receptors ranged between 2.2 and $4.5 \mathrm{impulses} / \mathrm{sec} / \mathrm{mm}$, with the mean of $3.5 \mathrm{impulses} / \mathrm{sec} / \mathrm{mm}$.

The dynamic index increased with increases of stretch velocity and also with initial length extension. FIG. 6 shows graphically the dependence of the magnitude of the dynamic index upon the stretch velocity for different initial lengths on a representative example of the lower threshold leaf-like receptor (solid lines).

The leaf-like receptor belonging to higher threshold group responded with one or a few discharges at the completion of the stretch even when the muscle stretched by $2 \mathrm{~mm}$ from $+6 \mathrm{~mm}$ initial length. When the muscle was stretched by $2 \mathrm{~mm}$ from $+8 \mathrm{~mm}$ initial length, several discharges appeared, as illustrated in FIG. 7. The initial transient rises of the discharge frequency were often observable in FIG. 7A, B and C.

Since the discharges did not maintain for $0.5 \mathrm{sec}$ after the completion of dynamic phase of the stretch even in $+6 \mathrm{~mm}$ initial length, the static index

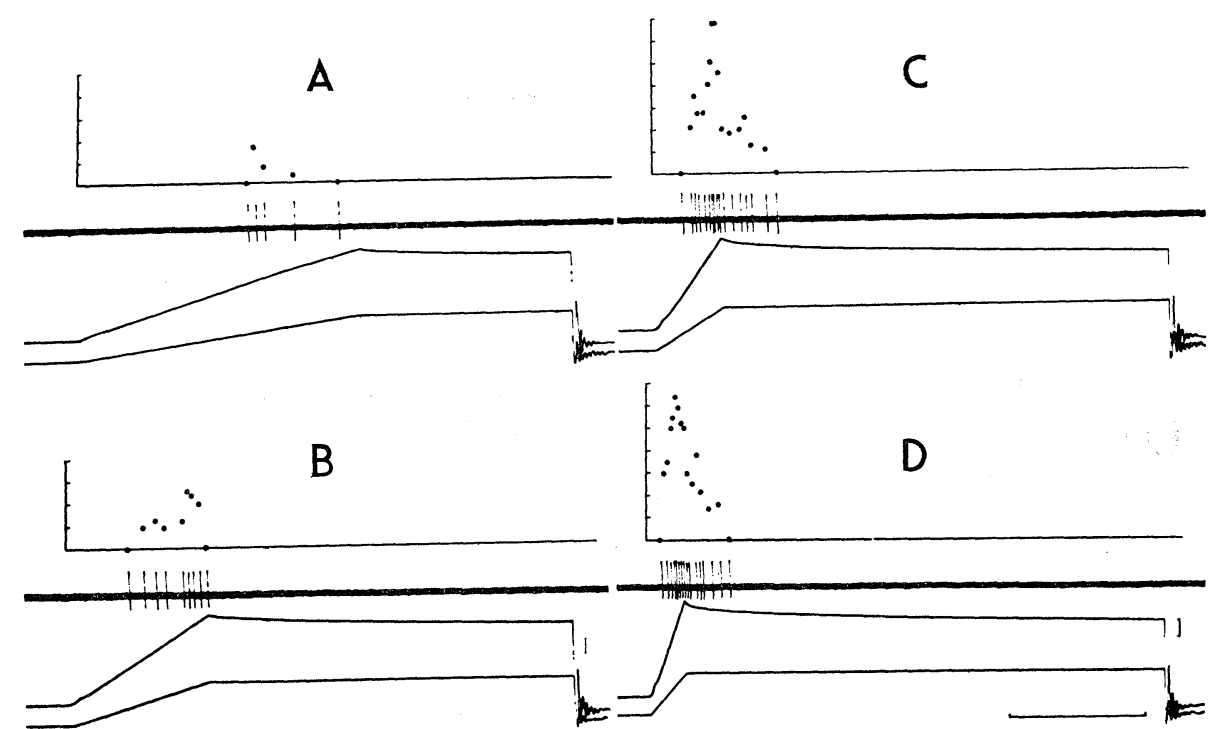

FIG. 7. Responces of a higher threshold leaf-like receptor (upper traces) during muscle stretch by $2 \mathrm{~mm}$ from $+8 \mathrm{~mm}$ initial length at the velocity of 1.0 (A), 2.0 (B), 4.0 (C) and $8.0 \mathrm{~mm} / \mathrm{sec}$ (D), recorded simultaneously with the displacement (lower traces) and the tension changes (middle traces) of the muscle. Calibration: $1 \mathrm{~g}$ for tension, $1 \mathrm{sec}$. The frequency is plotted on the head of each record. Scale: $10 \mathrm{impulses} / \mathrm{sec}$. 
was zero. The magnitude of the dynamic index was dependent upon the velocity of stretching and also upon the amount of initial length as illustrated with dotted lines in FIG. 6. The angle of the slope of the dynamic indexes to the stretch velocities appeared to be steeper than those of the lower threshold receptors.

\section{DISCUSSION}

There is general concurrence that the morphological variations observed in the complex unencapsulated ending probably represent adaptations to local anatomical configulations of receptors that may have similar functions whether they are located in tendon or in muscle ${ }^{10}$. HUBER and DEWITT ${ }^{3)}$ and HINSEY ${ }^{2)}$ have described complex unencapsulated endings in the frog tendon which resemble to the leaf-like receptors in the frog muscle described by KULCHITSKY ${ }^{7}$. Such a structural similarity between the tendon and the leaf-like receptors in the frog has been supported by the resemblance between their excitabilities (threshold, rate of adaptation and conduction velocity) in the preceding paper ${ }^{5}$. In the present study, however, the discharge patterns of the leaf-like receptors were distinguished from those of the tendon receptors during different mechanical deformations of the muscle. The functional differences between those receptors may be explained by the structural differences between the underlying tissues in which those sensory endings are embedded.

The leaf-like receptors are situated on the surface of the extrafusal muscle fibers. The response in the rising foot of the isometric twitch tension may occur when the contraction of the muscle fibers embedded with the receptor (serial forces) is followed by that of the other muscle fibers (parallel forces) in which some effects of contraction in the sensory region itself may be included. During the appearance of discharges the amount of the former contraction may exceed that of the latter, and the succeeding silent period of the response during the contraction of the muscle may be attributable to the parallel forse caused by the contraction of the latter surpassing the serial one. The response in the falling foot of the twitch tension may appear when the amount of contractions of the muscle fibers embedded with the receptor exceeded the amount of contraction of the other muscle fibers at a later period of the contraction of the muscle. It also seems that the increase of stimulus strength to the ventral root may result in increase of the number of activated muscle fibers and then may cause the acceleration of discharges from leaf-like expansions innervated by a parent afferent nerve fiber.

During passive stretch of the muscle, the response of the leaf-like receptor appeared with the lower threshold and a slower adaptation than that of the tendon receptor. Those differences may be due to the different visco-elastic properties of their underlying tissue. The property is represented well by the 
static and dynamic sensitivities of their responses, as has been pointed out in relation to the responses of the frog muscle spindle by ToYAMA ${ }^{11)}$. That the static sensitivity of the leaf-like receptor $(2.2-4.5 \mathrm{impulses} / \mathrm{sec} / \mathrm{mm})$ was apparently higher than that of the tendon receptor (generally 0, and 3.73 impulses/ $\mathrm{sec} / \mathrm{mm}$ in two receptors), shows that the elasticity of the sensory region of the leaf-like receptor may be higher than that of the tendon receptor. The dynamic sensitivity of the leaf-like receptor was also higher than that of the tenden receptor; because the dynamic index of the tendon receptor was slightly increased with prolongation of the initial length of the muscle whilst that of leaf-like receptor increased steeply with prolongation of the initial length and with increases of the stretch velocity. Therefore the viscosity of the muscle fiber embedded with the leaf-like receptor may be higher than that of the tendon. It was assumed from data of ToYAMA ${ }^{11)}$ that the static sensitivity of the muscle spindle was higher than that of the leaf-like receptor but the dynamic sensitivity of the former was lower than that of the latter. This suggests that the elasticity of the sensory region along the intrafusal muscle fiber may be higher than that of the extrafusal muscle fiber and the viscosity of the former may be lower than that of the latter. It has been demonstrated in the mammalian Pacinian corpuscle ${ }^{8}$, in muscle spindles in the cat and frog, ${ }^{9,11}$ and in frog skin receptors ${ }^{1)}$ that the functional properties of their receptors are attributable to the visco-elastic properties of the transmitting tissues between the mechanical stimulation and their receptors.

The response patterns of their receptors during muscle shortening against loads may be easily explained by the combination between the visco-elastic properties of their tissues and the balance between the serial and parallel forces. In the leaf-like receptors, the discharge frequency during the first upward deflection were often exceeded by that during the second deflection; in contrast with the tendon receptors which responded with only one discharge at the peak of the first upward deflection. It seems that the serial force extending the leaf-like receptors may be cancelled by the parallel forces during the first upward deflection but the receptors may be stretched by the falling load without the parallel forces during the second deflection.

\section{SUMMARY}

1. The properties of leaf-like receptors were studied by means of an analysis of the discharges recorded from the 9 th dorsal root in a frog sartorius muscle-nerve preparation.

2. During isometric contraction of the muscle, about $70 \%$ of the discharges from the receptors occurred at the falling phase of the tension curve, and $30 \%$ occurred at the rising phase.

3. During muscle shortening against loads, the leaf-like receptors were 
characterized by their responses in both the first and second upward tension deflections.

4. With muscle stretching at constant velocities, the static index increased linearly with increases of the initial length. The static sensitivity ranged from 2.2 to $4.5 \mathrm{impulses} / \mathrm{sec} / \mathrm{mm}$. The dynamic index was dependent upon the velocity of stretching and on the initial length.

5. The possibility that the excitability of the receptor may resemble that of the tendon receptor was discussed. The different discharge patterns from the two kinds of receptors during various mechanical stimulations may be due to the differences of contractile elements acting on their receptors and also to different visco-elastic properties of the tissues embedded with them.

I would like to express my sincere gratitude to Dr. P. BACH-Y-Rita in the Pacific Medical Center of San Francisco for his suggestions and for his correction of the English manuscript. Portions of this study were carried out at Pacific Medical Center, San Francisco, and supported by Public Health Service Research Grant NB 04671.

\section{REFERENCES}

1) Catton, W. T. and Petoe, N. A visco-elastic theory of mechanoreceptor adaptation. J. Physiol. 187 : 35-49, 1966.

2) Hinsey, J.C. The innervation of skeletal muscle. Physiol. Rev. $14: 514-585,1934$.

3) Huber, G.C. And DeWitt, L.M. A contribution on the nerve terminations in neuro-tendinous end-organs. J. Comp. Neurol. 10:159-208, 1900.

4) Ito, F., Toyama, K. AND Ito, R. A comparative study on structure and function between the extrafusal receptor and the spindle receptor in the frog. Jap.J. Physiol. $14: 12-33,1964$.

5) Iто, F. Functional properties of tendon receptors in the frog. Jap. J. Physiol. 18 : 576-598, 1968.

6) Kobayashi, Y., Oshima, K. And TAsaki, I. Analysis of afferent and efferent systems in the muscle nerve of the toad and cat. J. Physiol. 117: 152-171, 1952.

7) Kulchitsky, N. Nerve endings in the muscles of the frog. J. Anat. 59: 1-17, 1924.

8) Loewenstein, W. R. And Shelak, R. Mechanical transmission in a Pacinian corpuscle. An analysis and a theory. J. Physiol. 182: 346-378, 1966.

9) Matthews, P.B.C. Muscle spindles and their motor control. Physiol Rev. 44: 219-288, 1964.

10) Ralston III, H. J., Miller, M.R. and Kasahara, M. Nerve endings in human fasciae, tendons, ligaments, periosteum, and joint synovial membrane. Anat. Record. 136 : 137-147, 1960.

11) Toyama, K. An analysis of impulse discharges from the spindle receptor. Jap.J. Physiol. 16 : 113-125, 1966. 